\title{
New High Throughput Microtiter Plates for Detection of Organophosphorous Pesticides in Environmental Samples
}

\author{
Hassan A. Azab; Z. M. Anwar; Gasser M. Khairy and Osama Abd-el-Kader* \\ Chemistry Department, Faculty of Science, Suez Canal University, Ismailia, Egypt.
}

\author{
Received: $25 / 12 / 2015$
}

\begin{abstract}
Quenching of lanthanides luminescence of a novel long live Tb(III)- Ethyl 1-allyl-1,2-dihydro-4-hydroxy-2oxoquinoline-3-carboxylate (EADHOC) as a ligand to form a complex with molar ratio 1:3 in solution has been studied in ethanol in presence of organophosphorus pesticides both Di-chlorvos (P1) and paraoxon-Ethyl (P2). The intensity of luminescence of $\mathrm{Tb}(\mathrm{III})-(\mathrm{EADHOC})$ decrease as the concentration of pesticides increase. The quenching effect was observed with both pesticides. Direct methods of determination of pesticides under investigated have been developed by using luminescence of $\mathrm{Tb}(\mathrm{III})-(\mathrm{EADHOC})$ probe in a solution. The linear range for determination of the selected pesticides P1(Di-chlorovos) and P2(Paraoxon-Ethyl) is 7 and $1 \mu \mathrm{M}$. the detection limits were 1.9 and $9.8 \mu \mathrm{M}$ for P1(Dichlorovos) and P2 (Paraoxon-Ethyl) respectively. The Thermodynamic parameters and binding constant (K) of OPs with $\mathrm{Tb}(\mathrm{III})-(\mathrm{EADHOC})$ were evaluated. Including the value of enthalpy $(\Delta \mathrm{H})$ and entropy $(\Delta \mathrm{S})$ changes for Probe interaction with pesticides. As the natural water sample in this study don't contain the above mentioned OPs over the limit detected by the methods, a recovery study was carried out after the addition of the adequate amount of organophosphorus pesticides under investigation.
\end{abstract}

Keywords: Lanthanides ions, Microtiterplate and Organophosphorus pesticides \section{INTRODUCTION}

Organophosphorus pesticides (OPs) are used in a wide range in many fields especially in agriculture fields to improve the quality and quaintly of crops, However OPs are synthetic chemical compounds of esters, amides, or thiol derivatives of phosphoric, phosphonic, phosphorothioic or phosphonothioic acids. There are over 100 OPs. According to the chemical structural of organophosphorus pesticides it has a central phosphorus atom, with either double bonded oxygen $(\mathrm{P}=\mathrm{O})$, or a double bonded sulfur atom $(\mathrm{P}=$ $\mathrm{S}) . \mathrm{P}=\mathrm{O}$ pesticide is called an Oxon pesticide, and the $\mathrm{P}=\mathrm{S}$ is termed as thion pesticides (Sultatos, 1994).

Organophosphorus pesticides (OPs) compounds are highly powerful inhibitors of cholinesterase, and Ops have a very highly toxicity effect on human health and bad environmental effect. Organophosphorus pesticides with a Phosphoryl $(\mathrm{P}=\mathrm{O})$ function group such as (Di-Chlorvos and Paraoxon-Ethyl) wide spread and frequent commercial use of organophosphate based compound in agricultural lands and other environmental application, So it has resulted in their presence as residues in crops, soil and poultry products and severe risk to the aquatic environment as well as to drinking water quality. Thus, there remains a constant need for the determination of pesticide concentrations in natural water. The European Union (EU) has recently scheduled a monitoring based priority list containing those species of pesticides, which are considered to represent an exceptionally high risk to humans and to the aquatic environment (Eleršek and Filipi, 2006).

The design of new sensors with improved analyte sensitive and selective is a great importance in this area. Many analytical techniques were introduced to determination of organophosphorus pesticides (OPs) in water including gas chromatography-mass spectrometry (GC-MS) (Lopez et al., 2001; Becker et al., 1997; Albanis and Hela, 1995). High performance liquid chromatography (HPLC) and mass spectrometric
(LCMS) or diode array detection (LC-DAD) (Slobodnlk et al., 1996; Lacorte and Barcelo, 1995; Lagana et al., 1997; Maruyama, 1992; Martinez et al., 1992). A disadvantage of the HPLC, CE and GC analysis in general the analysis takes long time and limited sensitivity, costly and require high purity grade of organic solvents of HPLC (Pérez-Ruiz et al., 2005; López et al., 2001; Abdel-Halim et al., 2006). The lanthanides ions have specific characteristics of its luminescent for the narrow band emission and long life time of the excited state and also it form a stable complex (Mizukami et al., 2011; Miyata, 2014; Parker, 2000; Reisfeld, 2015; Azab et al., 2015).

Ethyl 1-allyl-1, 2-dihydro-4-hydroxy-2oxoquinoline-3-carboxylate (EADHOC) as shown in Figure (1) is a water-soluble and commercially available has a nitrogen and oxygen atoms that can coordinate to the metal ions. The excited light absorbed by EADHOC is transferred to its triplet state by the intersystem crossing, then intra-molecularly transferred to $\mathrm{Tb}$ (III) ion. The sensitized luminescence of widely applied in many fields, such as probes and labels in variety of biological and chemical applications (Binnemans, 2009; Hassan et al., 2013; Puntus et al., 2004). However the lanthanides complexes widely used to recognize the biological function in the body metabolism (Eldor, 1993; Chris, 1998; Sudhindra et al., 2004). And in a variety of process as enzyme inhibitors (Couper et al., 1994; Kazuhiro, 1994; Azab et al. 2011) And plant preservation.

In the present work, we have studied the interaction of Tb (III) - with Ethyl 1-allyl-1, 2-dihydro4-hydroxy-2-oxoquinoline-3-carboxylate (EADHOC) with different organophosphorus pesticides (OPs) by using luminescence spectroscopy. We focused our studies on two pesticides Di-chlorovos (P1) and Paraoxon-Ethyl (P2). The structures of the studied pesticides are shown in the Figure (2). However, this study is considered as a part of our project for 
development of chemo and biosensors for selective detection of organophsoporus pesticides in environmental samples (Ali et al., 2010; Azab et al., 2010a; Azab., 2010b; Azab et al., 2016).

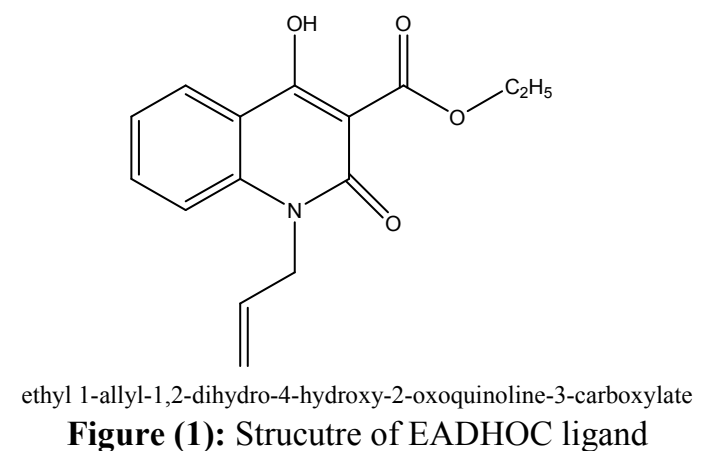

Figure (1): Strucutre of EADHOC ligand

\section{Pesticide}

Di-chlorovos (P1)

Paraoxon-ethyl (P2)

\section{2,2-dichlorovinyl dimethyl phosphate}

Diethyl 4-nitrophenyl phosphate

\section{Structure}<smiles>CCOP(=O)(OCC)Oc1ccc([N+](=O)[O-])cc1</smiles>

Figure (2): Strucutre of studied Pesticides

\section{MATERIALS AND METHODS}

\section{Reagents}

Ethyl 1-allyl-1, 2-dihydro-4-hydroxy-2oxoquinoline-3-carboxylate (EADHOC) and all OPS used were obtained from Sigma-Aldrich, St. Louis, Mo. USA. Standard certified pesticides of analytical grade were purchased from Sigma-Aldrich. (Hamburg, Germany) supplied certified reference items. The purity above $95 \%$ individual stock solution containing $0.1 \mu \mathrm{g}$ $\mathrm{mL}^{-1}$ analyte was prepared in high pure ethanol. Stock solutions $\left(1 \times 10^{-3} \mathrm{M}\right)$ of OPs were prepared by dilution of the standards using absolute ethanol. This solution was stable; however daily working solutions were prepared by dilution with absolute Ethanol. All solution were protected against light and humidity with aluminum foil and stored in a refrigerator. Lanthanide metal salt $\mathrm{TbCl}_{3} .6 \mathrm{H}_{2} \mathrm{O}$ was from Sigma Chemical co. A $1 \times 10^{-3} \mathrm{M}$ of standard solution of terbium chloride was prepared by dissolving a high-purity terbium chloride hexa-hydrate (from Merck, Darmstadt, Germany) in ethanol (from Sigma-Aldrish). Stock solutions of $\mathrm{Tb}$ (III)-EADHOC were freshly prepared by mixing appreciate amount of $\mathrm{TbCl}_{3}$ and the ligand followed by the stirring for about $30 \mathrm{~min}$. to form $\mathrm{Tb}$ (III)EADHOC. The Tb (III)-EADHOC-Pesticide solution were prepared by transferring of $0.05-1 \mathrm{~mL}$ aliquots of the pesticides working standard solution into a $10 \mathrm{~mL}$ volumetric flask followed by the addition of the required volume of $\mathrm{Tb}$ (III)-EADHOC Solution. The solution were shaking vigorously before irradiation and/or carrying out analytical measurements.

\begin{abstract}
Apparatus
All measurements were carried out on a Jasco 6300 spectrofluorimeter equipped with a $150 \mathrm{~W}$ Xenon lamp source and quartz cell of $1 \mathrm{~cm}$ path length. The slit widths of excitation and emission wave length were 5 $\mathrm{nm} / 5 \mathrm{~nm}$. All absorption spectra were performed on a perkin-Elmer lambda 20 UV-VIS spectrophotometer equipped with quartz cells. Software programs used for the statistical treatment of the data were stagraphics plus for windows 3.1 software package (Statistical Graphics Corporation, USm1994-1997) and Excel software package from Microsoft office 97, version 8.0,1997. Luminescence time-resolved measurements in microtiter plates (MTP) were performed using 96-well flat bottom black microplates. The instrument is equipped with the high Energy xenon flash lamp. The instrumental parameters of the MTP reader were as follows: excitation filter of $320 \pm 10 \mathrm{~nm}$, emission filter of $520 \pm 10 \mathrm{~nm}$, lag time $50 \mu \mathrm{s}$, Integration time $100 \mu \mathrm{s}$, 10 flashes per well, time gap between move and flash 100 ms. Luminescence top measurement mode was used and temperature was adjusted to $25^{\circ} \mathrm{C}$. The gain of the microtiter plate reader was fixed at a value of 1500 . The mean fluorescence intensity was calculated as the average of eight independent measurements of each concentration.
\end{abstract}

\section{Procedure}

The luminescence spectra and the intensities were monitored at the fixed analytical emission wave length $\left(\lambda_{\mathrm{em}}=545 \mathrm{~nm}\right)$ of the complex in $10 \mathrm{ml}$ of ethanol. 
Luminescence titrations were performed in $1 \mathrm{~cm}$ quartz cuvette by successive addition of pesticides $\left(1 \times 10^{-6}\right.$ $\left.1 \times 10^{-5} \mathrm{M}\right) \mathrm{Tb}$ (III) Chloride and $\left(1.0 \times 10^{-5} \mathrm{M}\right)$ of EADHOC. The titration data were analyzed according to modified Stern-Volmer equation to investigate the type of interaction of $\mathrm{Tb}$ (III)-Complex with the different pesticides. A1:3 stoichiometry of $\mathrm{Tb}$ (III): EADHOC was used in all experiments. The employed pesticides $\mathrm{P} 1$ and $\mathrm{P} 2$ seem to absorb the excitation light at $360 \mathrm{~nm}$ that may affect the luminescence intensity of $\mathrm{Tb}$ (III) by filtering effect. The analysis was done by using the decrease of luminescence intensity due to this effect as well as the quenching results from the interaction between the $\mathrm{Tb}$ (III)-EADHOC probe and studied pesticides in ethanol.

\section{RESULTS AND DISCUSSION}

\section{Interaction of EADHOC with Tb (III)}

\section{Steady State UV-vis spectroscopy}

The absorption spectrum of $3 \times 10^{-5} \mathrm{M}$ EADHOC as the free ligand in ethanol has maximum absorption band at $\lambda_{1}=320 \mathrm{~nm}, \lambda_{2}=350 \mathrm{~nm}$, the first band could be attributed to $\pi-\pi *$ transition while the second one is the characteristic band for $\mathrm{n}-\pi^{*}$ transition as shown in Figure (3). Upon addition of $1 \times 10^{-5} \mathrm{M}$ of $\mathrm{Tb}$ (III) to the ligand solution, the first band of the ligand is slightly shifted to the lower wavelength $(\lambda=316 \mathrm{~nm})$ with a decrease in the absorbance value, while the second band of the ligand become as a shoulder, hence such behavior is a good configuration of the binding of $\mathrm{Tb}$ (III) to the ligand molecule. The behavior of $\mathrm{Tb}$ (III)-Complex in ethanol solvent was monitored by UV-VIS Spectroscopy for several times at room temperature. Liberation of ligand wasn't observed under these conditions, so it suggests that the complex is stable under the conditions studies.

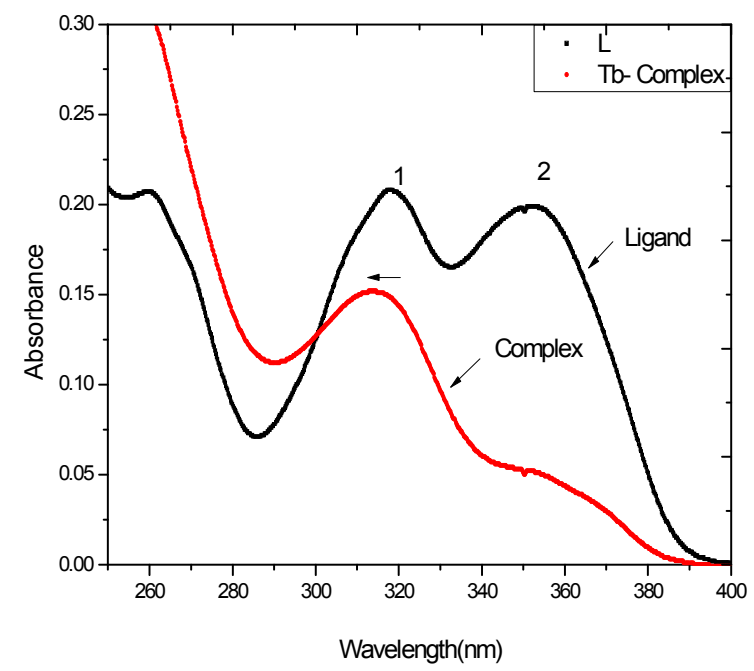

Figure (3): UV Absorption spectra of $\left(3 \times 10^{-5} \mathrm{M}\right)$ EADHOC $(\mathrm{L})$, and $\left(3 \times 10^{-5} \mathrm{M}\right)$ EADHOC $+\left(1 \times 10^{-5} \mathrm{M}\right) \mathrm{TbCl}_{3}$ in Ethanol at room temperature.

\section{Steady state luminescence spectroscopy}

The luminescence spectrum of the Tb (III) EADHOC probe investigated at room temperature in ethanol as shown in Figure (4). The best stoichiometry of the formed complex was monitored by fluorescence measurements, where the data reveal that the ligand: metal ratio which give the higher intensity $=545 \mathrm{~nm}$ is obtained at 3:1 Figure $(5 a, b)$.

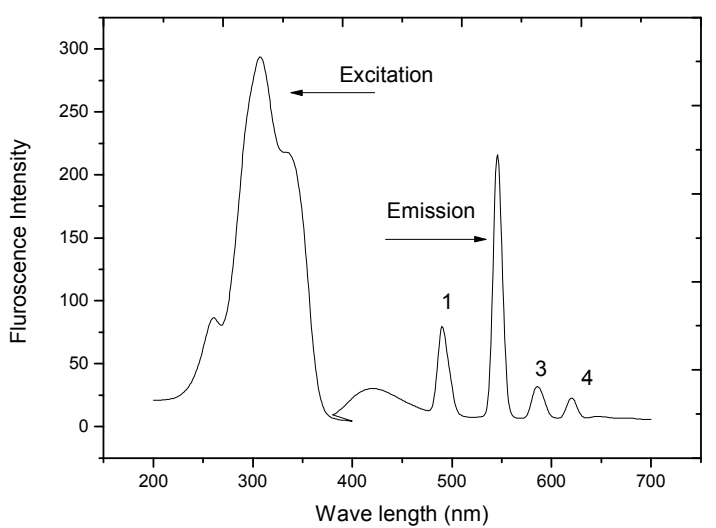

Figure (4): Fluorescence and Excitation spectra for $\mathrm{Tb}$ (III)-EADHOC in Ethanol $\left[\mathrm{C}_{\mathrm{Tb}}=1 \times 10^{-5} \mathrm{~mol} \mathrm{~L}^{-1}\right.$ and $\left.\mathrm{C}_{\text {EADHOC }}=3 \times 10^{-5} \mathrm{~mol} \mathrm{~L}^{-1}\right]$.
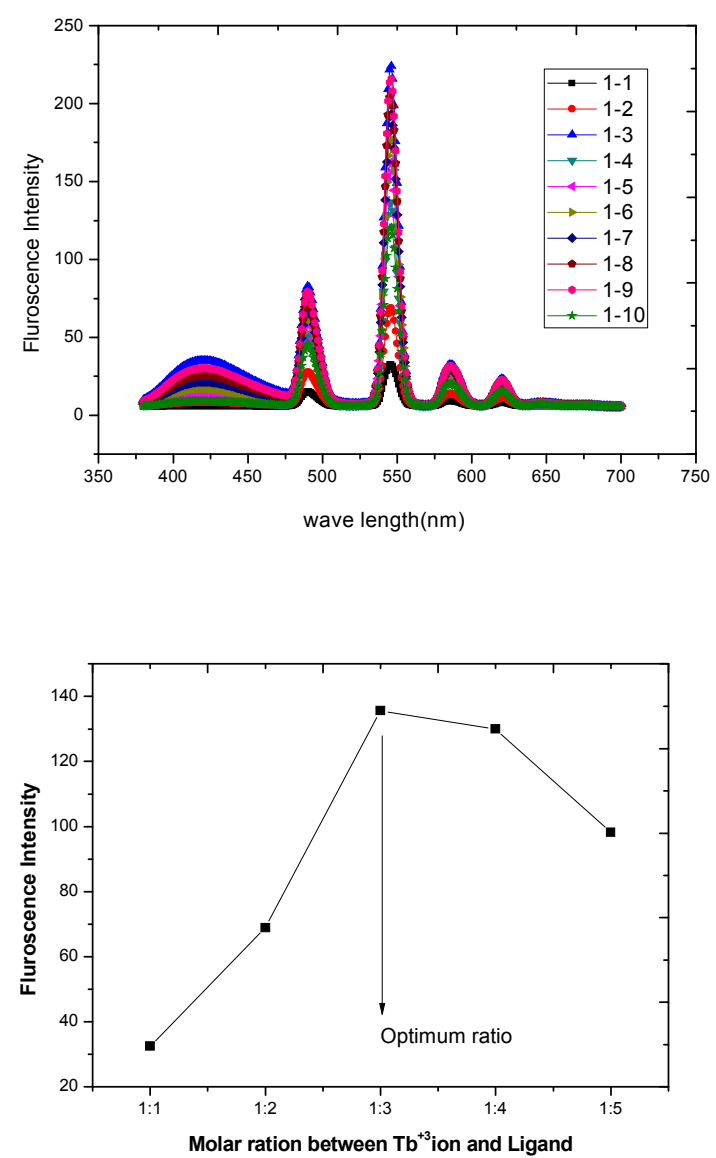

Figure (5): (a) Fluroscence spectra at ( $\lambda_{\mathrm{EX}}: 355 \mathrm{~nm}$ ) for $\mathrm{Tb}$ (III)-Complex with different concentration of EADHOC ligand $\left[\mathrm{C}_{\mathrm{Tb}(\mathrm{III})}=1 \times 10^{-5} \mathrm{~mol} \mathrm{~L}^{-1}\right.$ and $\mathrm{C}_{\text {EADHOC }}=1,2,3,4$ and $\left.5 \times 10^{-5}\right]$.

(b) Jop's method. 
Interaction of Tb (III)-EADHOC probe with different pesticides

\section{Luminescence spectroscopy of Tb (III)-EADHOC} Probe with different pesticides

The effect of the studied two Organophosphorus pesticides (OPs) on the luminescence intensity of $\mathrm{Tb}(\mathrm{III})$-EADHOC probe has been investigated in ethanol solvent, they show quenching effect on intensity of $\mathrm{Tb}$ (III)-EADHOC probe as shown in Figure (6).

\section{Luminescence quenching and calibration curve for} organophosphorus pesticides.

The effect of different pesticides concentration on the intensity of luminescence of $\mathrm{Tb}$ (III) complex exhibited a pronounced change in the emission intensity in ethanol solvent as appear in Figure (6) at experimental conditions. The decrease of the luminescence intensity of $\mathrm{Tb}$ (III)-EADHOC after adding pesticides may be attributed to a combined effect including both photo- absorption by the solute and the possible interaction with the pesticides by additional coordination with $\mathrm{Tb}$ (III)-EADHOC which may take place at $(\mathrm{P}=\mathrm{O})$ functional group. The luminescence intensity decrease due to its chelation to the receptor unit of the sensor and formation of a non-luminescent complex and therefore the net luminescent is quenched. However the quenching process can be classified into two types according to their mechanism, static and dynamic quenching. Both of two types distinguished by their different dependences on the temperature and excited life time. Dynamic quenching is diffusion controlled because the quencher must be diffuse to the fluorophore during the lifetime of the excited state. So high temperature mean more diffusion coefficient. However the bimolecular quenching constant are expected to increase with temperature while if $\left(\mathrm{K}_{\mathrm{sv}}\right)$ decrease with increase temperature, the quenching process is static rather than dynamic (Rui $\mathrm{Yu}$ et al., 2015; Siddiqi et al., 2009; Miller and Miller, 1993). Statics quenching implies either existence of a sphere of effective quenching where dynamics or collisional quenching involve the collision followed by the formation of a transient complex between an excitedstate fluorophore and a ground state quencher. The effect of temperature on the stern-volmer quenching constant $\left(\mathrm{K}_{\mathrm{SV}}\right)$ was examined for the two pesticides as calculated from the obtained data (Figures 7 and 8). The data reveal that the mechanism of quenching for Dichlorovos is static, on other hand dynamic or collisional quenching is that for Paraoxon-Ethyl.

Under optimum conditions, the calibration graphs are desired by equation: $\mathrm{Y}=\mathrm{a}+\mathrm{bX}$ (where $\mathrm{Y}=\mathrm{F} 0 / \mathrm{F}, \mathrm{a}=$ intercept, $\mathrm{b}=$ slope and $\mathrm{x}=$ concentration of pesticides in M).The limit of detection (LOD) calculated for Dichlorvos and paraoxon-ethyl pesticides in ethanol are1.9 and $9.8 \mu \mathrm{M}$ respectively and limit of quantitation (LOQ) for Di-chlorvos and paraoxon-ethyl pesticides are 6.5 and $1.3 \mu \mathrm{M}$ respectively.

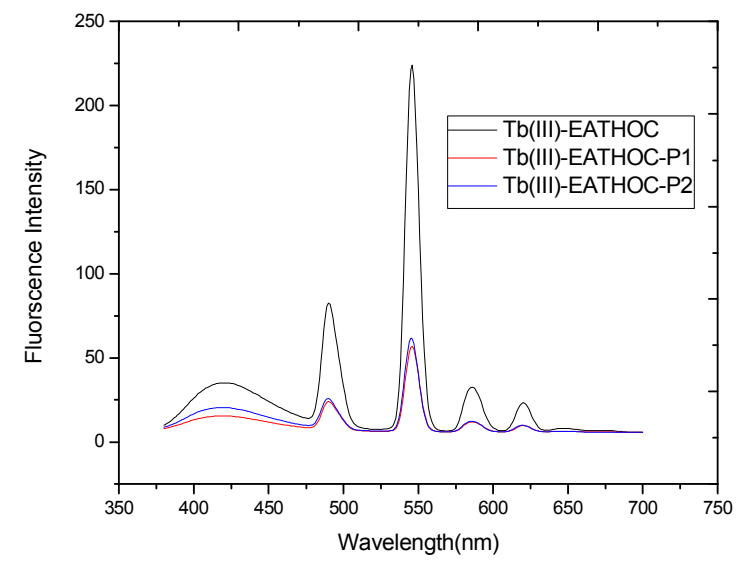

Figure (6): Emission spectra of free Tb (III)-EADHOC and its interaction with Paraoxon-ethyl and Dichlorvos pesticides in ethanol $\left[\mathrm{C}_{\mathrm{Tb}(\mathrm{III})}=1 \times 10^{-5} \mathrm{~mol} \mathrm{~L}^{-1}, \mathrm{C}_{\mathrm{EADHOC}}=\right.$ $3 \times 10^{-5}$ and $\left.\mathrm{C}_{\text {pesticides }}=1 \times 10^{-6} \mathrm{~mol} \mathrm{~L}^{-1}\right]$.

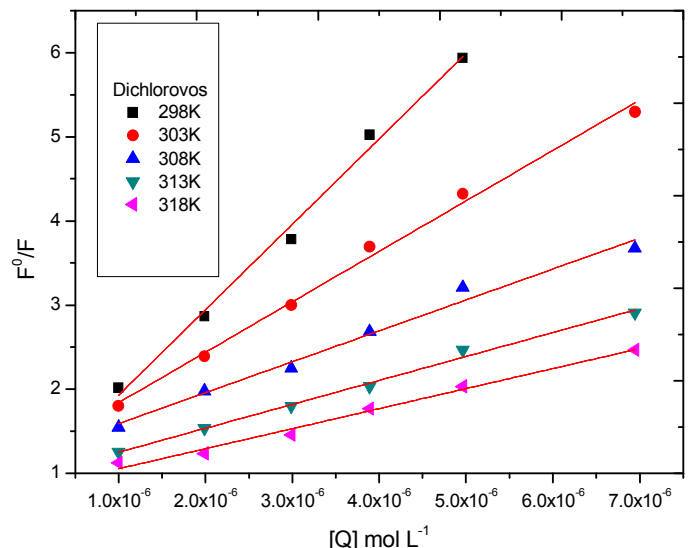

Figure (7): Steren-Volmercalibration plot for detection of Paraoxon-Ethyl using Tb (III)-EADHOC Complex in Ethanol at different temperature.

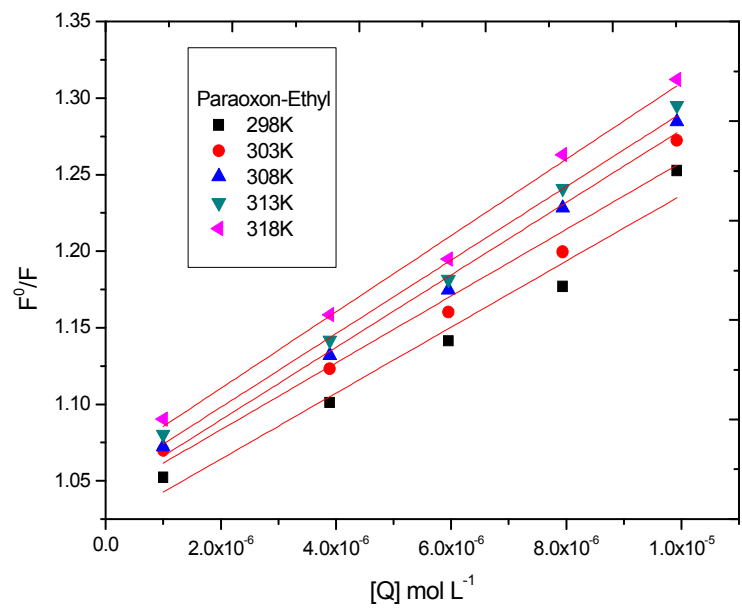

Figure (8): Steren-Volmercalibration plot for detection of Paraoxon-Ethyl using Tb (III)-EADHOC Complex in Ethanol at different temperature. 
Determination of binding parameters of $\mathrm{Tb}$ (III)EADHOC-complex with Di-chlorovos.

Quenching of luminescence intensity of $\mathrm{Tb}$ (III)EADHOC in presence of different concentrations of Dichlorovoscan be analyzed to obtain various binding parameters according to the following equation (Wei et al., 2000; Xiaohui et al., 2014).

$$
\log \left[\frac{\mathrm{F}-F}{F}\right]=\log K+n \log [Q]
$$

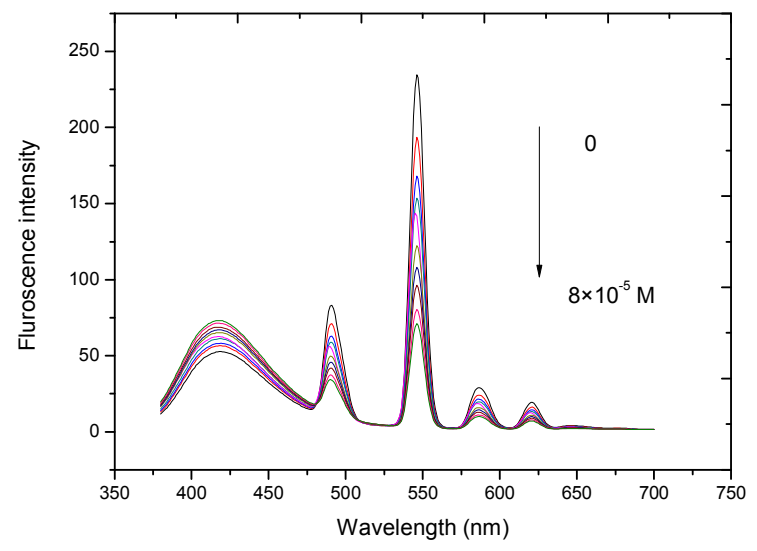

Where $\mathrm{K}$ and $\mathrm{n}$ are the binding constant and the number of binding sites respectively the plot of $\log \mathrm{F}^{0}-\mathrm{F} / \mathrm{F}$ versus Log [Q] gave a straight as shown in Figure (9).

Slope of such curve equal to $\mathrm{n}$ while the intercept equal to $\log \mathrm{K}$. The values of $\mathrm{n}$ approximately equal to 2 indicating that there is two binding sites in $\mathrm{Tb}$ (III)EADHOC for the selected pesticide P1 as in Table (1).

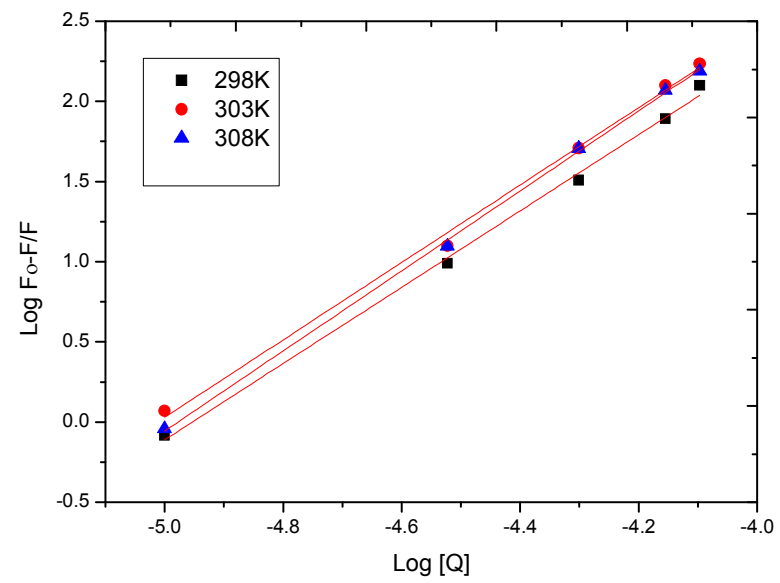

Figure (9): Effect of concentration of Di-Chlorvos pesticide on the emission spectra of Tb (III)-EADHOC in Ethanol at $25^{\circ} \mathrm{C}\left(\lambda_{\mathrm{EX}}=355 \mathrm{~nm}\right)$

Table (1): Binding parameters of Tb (III)-EADHOC with Di-chlorovos (P1) pesticide.

\begin{tabular}{lccccc}
\hline Pesticides & Temperature (K) & $\mathbf{K}\left(\times \mathbf{1 0}^{\mathbf{4}} \mathbf{M}^{-\mathbf{1}}\right)$ & $\mathbf{n}$ & $\mathbf{r}$ & $\mathbf{S D}(\boldsymbol{\sigma})$ \\
\hline P1 & 298 & 1.7 & 2.3 & 0.996 & 0.03 \\
& & & & & \\
& 303 & 1.27 & 2.41 & 0.995 & 0.07 \\
& & & & & \\
& 308 & 1.21 & 2.5 & 0.999 & 0.03
\end{tabular}

$\mathrm{SD}(\sigma)$ is a standard deviation.

Determination of thermodynamics parameters for the interaction of Tb (III)-EADHOC-with DiChlorovos pesticide.

The interaction of $\mathrm{Tb}$ (III)-EADHOC with Dichlorovos may proceed through hydrophobic interaction force either van der waales or hydrogen bond (Creighton, 1993). Thermodynamics parameters can be calculated using Van't Hoff equation

$$
L n K=-\frac{\Delta H}{R T}+\frac{\Delta S}{R}
$$

Where $\mathrm{R}$ is the gas constant, $\mathrm{T}$ is the experimental temperature, and $\mathrm{K}$ is the binding constant at the corresponding temperature as shown in Table (2).

$\Delta H$ and $\Delta S$ are enthalpy and entropy change of reaction

\section{Interference of other relevant metal ions}

To study the effect of the interference of other ions present in real sample a systematic study proceed on samples containing $1 \times 10^{-5} \mathrm{M}$ P1 Di-chlorovos and P2Paraoxon-Ethyl by Tb(III)-EADHOC at different concentration levels depending on their respective solubilizes as shown in Tables (3 and 4). 
Table (2): Binding constant $\left(\mathrm{K}_{\mathrm{D}}\right)$ and thermodynamics parameters for the interaction of Tb-Complex with the Dichlorovos.

\begin{tabular}{|c|c|c|c|c|c|c|}
\hline \multirow[t]{2}{*}{ Pesticides } & Temperature & \multirow{2}{*}{$\frac{\mathrm{K}_{\mathrm{D}}}{\left(\mathrm{Lmol}^{-1}\right)}$} & \multirow[t]{2}{*}{$\mathbf{R}$} & \multirow{2}{*}{$\frac{\Delta G \square}{(\mathrm{KJ} / \mathrm{mol})}$} & \multirow{2}{*}{$\frac{\Delta \mathbf{H o}}{(\mathrm{KJ} / \mathrm{mol}}$} & \multirow{2}{*}{$\frac{\Delta \text { So }}{(\mathrm{J} / \mathrm{mol} \mathrm{K})}$} \\
\hline & (k) & & & & & \\
\hline \multicolumn{7}{|c|}{ Di-chlorovos (P1) } \\
\hline & 298 & $9.78 \times 10^{5}$ & 0.9057 & -35.09 & & \\
\hline & 303 & $8.17 \times 10^{5}$ & 0.9752 & -35.2 & & \\
\hline & 308 & $7.41 \times 10^{5}$ & 0.9377 & -35.5 & -21.6 & 44.9 \\
\hline & 313 & $6.81 \times 10^{5}$ & 0.9585 & -35.9 & & \\
\hline & 318 & $6.1 \times 10^{5}$ & 0.9970 & -36.01 & & \\
\hline
\end{tabular}

Table (3): Recovery and tolerance of Di-chlorvos $(10 \mu \mathrm{mol} / \mathrm{L})$ using Tb (III) - EADHOC complex in the presence of different interfering species.

\begin{tabular}{|c|c|c|c|c|}
\hline \multirow{2}{*}{ Interfering species } & \multirow{2}{*}{$\mathbf{F}^{\mathbf{o}}$} & \multicolumn{2}{|c|}{$\begin{array}{c}\text { Concentration of an } \\
\text { interfering species }\end{array}$} & \multirow{2}{*}{ Tolerance } \\
\hline & & $1 \mu \mathrm{M}$ & $2 \mu \mathrm{M}$ & \\
\hline $\mathrm{Co}^{+2}$ & 54.4836 & 53.8354 & 53.3911 & $3 \mu \mathrm{M}(0.174 \mu \mathrm{g} / \mathrm{ml})^{\mathrm{Q}}$ \\
\hline $\mathrm{Cd}^{+2}$ & 112.044 & 111.435 & 102.849 & $3 \mu \mathrm{M}(0.337 \mu \mathrm{g} / \mathrm{ml})^{\mathrm{Q}}$ \\
\hline $\mathrm{Cu}^{+2}$ & 56.8326 & 56.551 & 52.8315 & $3 \mu \mathrm{M}(0.19 \mu \mathrm{g} / \mathrm{ml})^{\mathrm{Q}}$ \\
\hline $\mathrm{Hg}^{+2}$ & 62.6095 & 59.2308 & 56.0091 & $2 \mu \mathrm{M}(0.4 \mu \mathrm{g} / \mathrm{ml})^{\mathrm{Q}}$ \\
\hline $\mathbf{K}^{+}$ & 54.8205 & 53.5068 & 48.0075 & $2 \mu \mathrm{M}(0.078 \mathrm{Mg} / \mathrm{ml})^{\mathrm{Q}}$ \\
\hline $\mathrm{Na}_{2} \mathrm{CO}_{3}$ & 55.499 & 54.3903 & 52.6241 & $4 \mu \mathrm{M}(0.424 \mu \mathrm{g} / \mathrm{ml})^{\mathrm{Q}}$ \\
\hline $\mathrm{Na}_{2} \mathrm{HPO}_{4}$ & 55.2254 & 52.7138 & 48.6147 & $2 \mu \mathrm{M}(0.28 \mu \mathrm{g} / \mathrm{ml})^{\mathrm{Q}}$ \\
\hline $\mathrm{NaCl}$ & 54.762 & 51.0818 & 48.735 & $4 \mu \mathrm{M}(0.23 \mu \mathrm{g} / \mathrm{ml})^{\mathrm{Q}}$ \\
\hline $\mathrm{Na}_{2} \mathrm{So}_{4}$ & 55.894 & 55.476 & 50.7206 & $2 \mu \mathrm{M}(0.28 \mu \mathrm{g} / \mathrm{ml})^{\mathrm{Q}}$ \\
\hline $\mathrm{NH}_{4} \mathrm{Cl}$ & 48.5206 & 45.5185 & 43.9488 & $3 \mu \mathrm{M}(0.160 \mu \mathrm{g} / \mathrm{ml})^{\mathrm{Q}}$ \\
\hline $\mathrm{Ni}^{+2}$ & 110.094 & 103.468 & 100.975 & $3 \mu \mathrm{M}(0.17 \mu \mathrm{g} / \mathrm{ml})^{\mathrm{Q}}$ \\
\hline $\mathbf{P b}^{+2}$ & 84.5201 & 82.9189 & 74.9271 & $3 \mu \mathrm{M}(0.62 \mu \mathrm{g} / \mathrm{ml})^{\mathrm{Q}}$ \\
\hline
\end{tabular}


Table (4): Recovery and tolerance of Paraoxon-Ethyl $(10 \mu \mathrm{mol} / \mathrm{L})$ using $\mathrm{Tb}(\mathrm{III})-\mathrm{EADHOC}$ complex in the presence of different interfering species.

\begin{tabular}{|c|c|c|c|c|}
\hline \multirow{2}{*}{ Interfering species } & \multirow{2}{*}{$\mathbf{F}^{\mathbf{o}}$} & \multicolumn{2}{|c|}{$\begin{array}{l}\text { Concentration of an } \\
\text { interfering species }\end{array}$} & \multirow{2}{*}{ Tolerance } \\
\hline & & $1 \mu \mathrm{M}$ & $2 \mu \mathrm{M}$ & \\
\hline $\mathrm{Co}^{+2}$ & 58.8511 & 51.3252 & 45.801 & $3 \mu \mathrm{M}(0.174 \mu \mathrm{g} / \mathrm{ml}) \mathrm{Q}$ \\
\hline $\mathrm{Cd}^{+2}$ & 66.10 & 55.121 & 52.025 & $1 \mu \mathrm{M}(0.11125 \mu \mathrm{g} / \mathrm{ml}) \mathrm{Q}$ \\
\hline $\mathrm{Cu}^{+2}$ & 71.6022 & 70.120 & 62.923 & $3 \mu \mathrm{M}(0.19 \mu \mathrm{g} / \mathrm{ml}) \mathrm{Q}$ \\
\hline $\mathrm{Hg}^{+2}$ & 60.30 & 51.380 & 46.30 & $3 \mu \mathrm{M}(0.6 \mu \mathrm{g} / \mathrm{ml}) \mathrm{Q}$ \\
\hline $\mathbf{K}^{+}$ & 68.301 & 65.69 & 54.79 & $2 \mu \mathrm{M}(0.078 \mu \mathrm{g} / \mathrm{ml}) \mathrm{Q}$ \\
\hline $\mathrm{Na}_{2} \mathrm{CO}_{3}$ & 73.6 & 67.61 & 57.3 & $2 \mu \mathrm{M}(0.21 \mu \mathrm{g} / \mathrm{ml}) \mathrm{Q}$ \\
\hline $\mathrm{Na}_{2} \mathrm{HPO}_{4}$ & 66.101 & 60.22 & 51.205 & $2 \mu \mathrm{M}(0.28 \mu \mathrm{g} / \mathrm{ml}) \mathrm{Q}$ \\
\hline $\mathrm{NaCl}$ & 61.39 & 52.033 & 48.11 & $2 \mu \mathrm{M}(0.12 \mu \mathrm{g} / \mathrm{ml}) \mathrm{Q}$ \\
\hline $\mathrm{Na}_{2} \mathrm{So}_{4}$ & 64.78 & 60.6 & 53.34 & $2 \mu \mathrm{M}(0.24 \mu \mathrm{g} / \mathrm{ml}) \mathrm{Q}$ \\
\hline $\mathrm{NH}_{4} \mathrm{Cl}$ & 60.561 & 57.8 & 53.06 & $4 \mu \mathrm{M}(0.21 \mu \mathrm{g} / \mathrm{ml}) \mathrm{Q}$ \\
\hline $\mathrm{Ni}^{+2}$ & 62.86 & 58.6 & 44.9 & $2 \mu \mathrm{M}(0.12 \mu \mathrm{g} / \mathrm{ml}) \mathrm{Q}$ \\
\hline $\mathbf{P b}^{+2}$ & 64.9 & 62.05 & 56.9 & $3 \mu \mathrm{M}(0.62 \mu \mathrm{g} / \mathrm{ml}) \mathrm{Q}$ \\
\hline
\end{tabular}

\section{Applications}

The proposed methods was applied to determination of organophosphorus pesticides P1(Dichlorvos) and P2 (Paraoxon-Ethyl) in different types of water (tap water, mineral water and sediment) as water in this study didn't contain the studied pesticides OPs a recovery was carried out after addition of the adequate amount of pesticides under investigation. The analysis performed after the addition of P1 (Di-chlorvos) and P2 (Paraoxon-Ethyl) in water samples as the result obtain as shown in Table (5).

\section{CONCLUSION}

These papers describe the application of $\mathrm{Tb}$ (III)EADHOC luminescence quenching for sensing organophosphorus pesticides in ethanol solvent. The luminescence changes observed on adding of P1 (Dichlorovos) and P2 (Paraoxon-Ethyl) may use for detection of this analytes. However this method has many advantages as it cheap, rapid direct for determination of the pesticides The linear range for determination of the selected pesticides P1 (Dichlorovos)and P2 (Paraoxon-Ethyl) is 7and $1 \mu \mathrm{M}$. the detection limits were 1.9 and $9.8 \mu \mathrm{M}$ for P1 (Dichlorovos) and P2 (Paraoxon-Ethyl) respectively.Also this method was applied to determination of organophosphorus pesticides P1 (Di-chlorovos) and P2 (Paraoxon-Ethyl) in different types of natural water sample (tap water, mineral water and sediment) as water in this study didn't contain the studied pesticides OPs a recovery was carried out after addition of the adequate amount of pesticides under investigation. 
Table (5): Recovery of organophosphorus pesticides in different type of natural water sample.

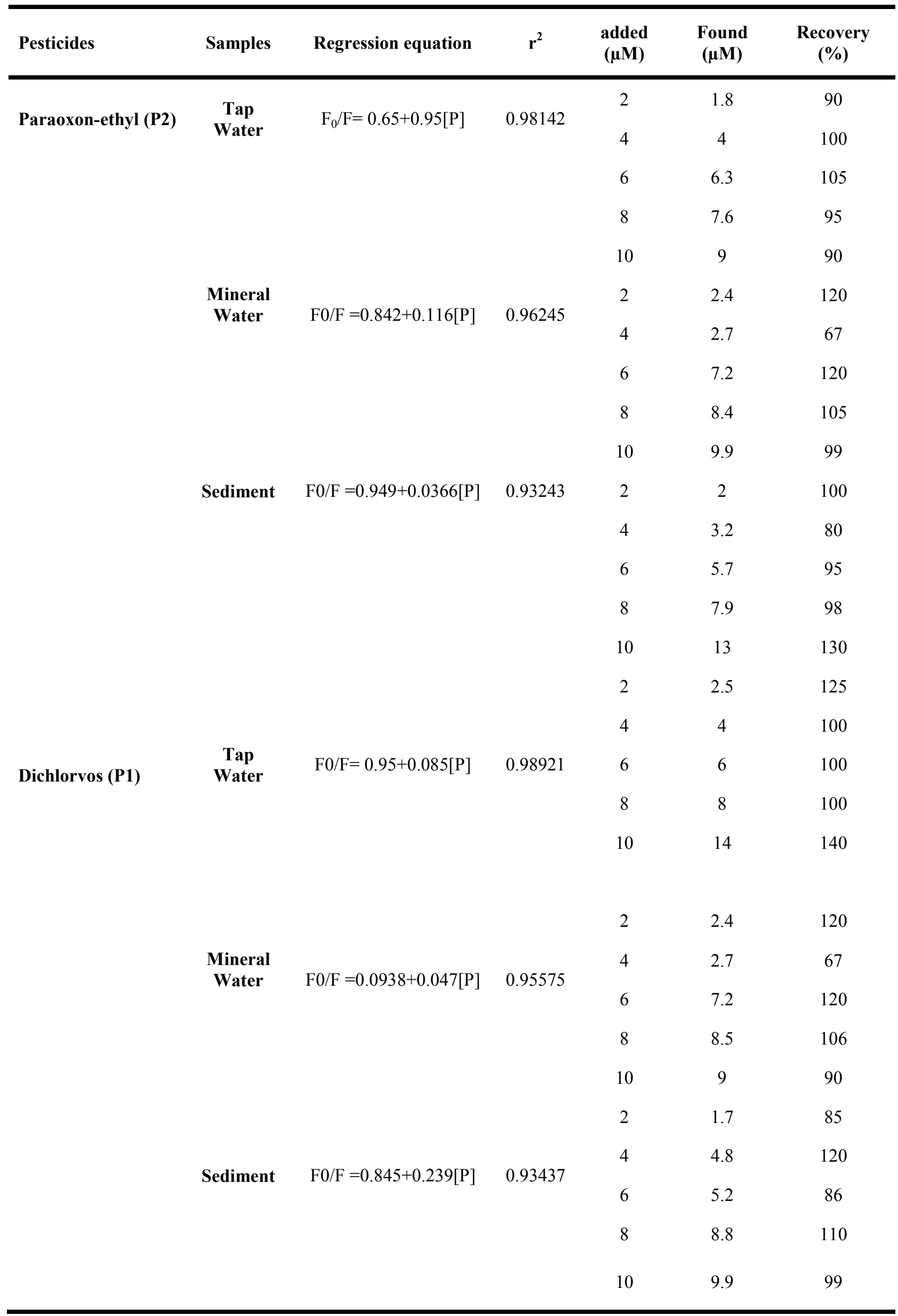




\section{REFERENCES}

Abdel-Halim, K. Y., A. K. Salama and E. N. ElKhateeb and N. M. Bakry (2006). Organophosphorus pollutants (OPP) in aquatic environment at Damietta Governorate, Egypt: Implications for monitoring and biomarker responses. Chemosphere, 63(9): 1491-1498.

Albanis, T. A. and D. G. Hela (1995). Organophosphorus pollutants (OPP) in aquatic environment at Damietta Governorate, Egypt: Implications for monitoring and biomarker responses. J. Chromatography A, 707: 283-292.

Ali, R., S. M. Saleh, R. J. Meier, H. A. Azab, I. I. Abdelgawad and O. S. Wolfbeis (2010). Upconverting nanoparticle based optical sensor for carbon dioxide. Sens. Actuators B, 150(1): 126-131.

Azab, H. A., G. M. Khairy and R. M. Kamel (2015). Time-resolved fluorescence sensing of pesticides chlorpyrifos, crotoxyphos and endosulfan by the luminescent $\mathrm{Eu}(\mathrm{III})-8$-allyl-3-carboxycoumarin probe. Spectrchim Acta A Mol Biomol Spectrosc., 148: 114-124

Azab, H. A., S. A. El-Korashry, Z. M. Anwar, B. H. M. Hussein.and G. M. Khairy (2010a). Eu (III)Anthracene-9-carboxylic Acid as a Responsive Luminescent Bioprobe and Its Electroanalytical Interactions with N-Acetyl Amino Acids, Nucleotides, and DNA. J. Chem. Eng. Data, 55(9): 3130-3141.

Azab, H. A., S. A. El-korashy, Z. M. Anwar, B. H. M. Hussein and G. M. Khair (2010b). Synthesis and fluorescence properties of Eu-anthracene-9carboxylic acid towards $\mathrm{N}$-acetyl amino acids and nucleotides in different solvents. Spectrochim.Acta part A: Mol. Biomol. Spectrosc., 75(1): 21-27.

Azab, H. A., S. A. El-korashy, Z. M. Anwar, G. M. Khairy, M. S. Steiner and A. Duerkop (2011). High-throughput sensing microtiter plate for determination of biogenic amines in seafood using fluorescence or eye-vision. Analyst, 136(21): 4492-4499.

Azab, H. A., Z. M. Anwar, R.M.Kamel (2016). Sensitive and selective fluorescent chemosensor for the detection of some organophosphorus pesticides using luminescent Eu(III) complex. Journal of Photochemistry and Photobiology A: Chemistry, 321(1): 33-40.

Becker, G., A. Colmsjo and C. Ostman (1997). Elemental composition determination of organophosphorus compounds using gas chromatography and atomic emission spectrometric detection. Analytical. Chimica Acta, 340(1-2): 181-189.

Binnemans, K. (2009). Lanthanide-based luminescent hybrid materials. Journal of Chem.Rev.,109(9):4283-4374.

Chris, K. (1998). Basics of Toxicology. Jhone Wiley and sons, 416.

Couper, L., J. E. Mckendrick and D. J. Robins (1994). Pyridine and Piperidine-Dervitives as inhibitors of dihydipicoliinic acid synthase, a key enzyme in the diaminopimelate pathway to 1-lysine. Bioorg. Med. Chem. Lett., 4(19): 2267-2272.

Creighton, T. E. (1993). Proteins: Strcutures and molecular properties. ( $2^{\text {nd }}$ ed.) Freeman, NewYork.

Eldor, A. P. (1993). Soil Microbiology, Ecology and Biochemistry. Micobiol, Text book, $3^{\text {rd }}$ eddition, Acdamemic press, 4: 1-33.

Eleršek, T. and M. Filipi (2006). Organophosphorus Pesticides - Mechanisms of Their Toxicity. Journal of National Institute of Biology Slovenia, 12: 243-260.

Hassan, A. A., A. Duerkopb, Z. M. Anwar, B. H. M. Hussein, M. A. Rizk and T. Amina (2013). Luminescence recognition of different organophosphorus pesticides by the luminescent Eu(III)-pyridine-2,6-dicarboxylic acid probe. Journal of Analytical Chemica Acta, 759(8): 8191.

Kazuhiro, K., Y. Noriko and F. Tadayasu (1994). Preservative for plants. Europ. Patent, EP0603165.

Lacorte, S. and D. Barcelo (1995). Determination of organophosphorus pesticides and their transformation products in river waters by automated on-line solid-phase extraction followed by thermospray liquid chromatographymass spectrometry. Journal of Chromatography A, 712(1): 103-112.

Lagana, A., G. D. Ascenzo, G. Fago and A. Marino (1997). Determination of organophosphorus pesticides and metabolites in crops by solidphase extraction followed by liquid chromatography/Diode array detection. Chromatographia, 46(5/6): 256-264.

López, F. J., E. Pitarch, S. Egea, J. Beltran and F. Hernández (2001). Gas Chromatographic determination of organochlorine and organophosphorus pesticides in human fluids using solid phase microextraction. Analytica Chimica Acta, 433(2): 217-226.

Martinez, R. C., E. R. Gonzalo, M. J. Amigo Moran and M. J. Hernandez (1992). Sensitive method for the determination of organophosphorus pesticides in fruits and surface waters by high-performance liquid chromatography with ultraviolet detection. J. Chromatogr., 607(1): 37-45.

Maruyama, M. (1992). Determination of trace amounts of 3,4-dichloroaniline by high-performance liquid chromatography with amperometric detection and its application to pesticide residue analysis. Journal of Analytical Chemistry, 343: 890-892.

Mille, J. C. and J. N. Miller (1993). Significance Tests Chapter 3. In: Statistics in Analytical Chemistry, $3^{\text {rd }}$ ed., 233 pp. Chichester Ellis Horwood PTR Prentice Hall.

Miyata, K. (2014). HighlyLuminescent lanthanide Complexes with Specific Coordination Structures. XIII, 91 p. Springer Theses Ser., Japan.

Mizukami, S., T. Yamamoto, A. Yoshimura, S. 
Watanabe and K. Kikuchi (2011). Covalent protein labeling with a lanthanide complex and its application to photoluminescencelifetimebased multicolor bioimaging; Angew. Chemie Int. Ed. Engl., 50(37): 8750-8752.

Parker, D. (2000). Luminescent lanthanide sensors for $\mathrm{pH}, \mathrm{pO} 2$ and selected anions. Coord. Chem. Rev., 205(1): 109-130.

Pérez-Ruiz, T., C. Martínez-Lozano, V. Tomás and J. Martín (2005). High-performance liquid chromatographic assay of phosphate and organophosphorus pesticides using a postcolumn photochemical reaction and fluorimetric detection. Analytica Chimica Acta, 540(2): 383391.

Puntus, L. N., V. F. Zolin, T. A. Babushkina and I. B. Kutuza (2004). Luminescence properties of isomeric and tautomeric lanthanide pyridinedicarboxylates. J. Alloys Compd., 380 (1-2): 310-314

Reisfeld, R. (2015). Optical Properties of Lanthanides in Condensed Phase, Theory and Applications. AIMS Mater. Sci., 2(2): 37-60.

Rui Yu, Qiang Liu, Jingshuang Liu, Qicum Wang, Yang Wang (2016). Concentrations of organophosphorus pesticides in fresh vegetables and related human health risk assessment in Changchun, Northeast China. Food Control, 60: 353-360.

Siddiqi, K. S., S. Bano, A. Mohd and A. A. Khan (2009). Binding interaction of captopril with metal ions: A fluorescence quenching study. P. Chin, J. Chem., 27(9): 1755-1761.

Slobodnik, J., A. C. Hogenboom, J. J. Veruls, J. A. Rontree, B. L. M van Baar, W. M. A. Niessen and U. A. Th. Brinkman (1996). Trace-level determination of pesticide residues using on-line solid-phase extraction-column liquid chromatography with atmospheric pressure ionization mass spectrometric and tandem mass spectrometric detection. Journal of Chromatography A, 741(1): 59-74.

Sudhindra, N. M., Minaz A. Gagnani, Indria Devi M and Ram S. Shukla (2004). Biological and Clinical Aspects of Lanthanide Coordination Compounds. Bioinorg Chem Appl., 2(3-4): 155192.

Sultatos L. G. (1994). Mammalian toxicology of organophosphorus pesticides. Journal of Toxicology and Environmental Health, 43: 271289.

Wei, X. F. and H. Z. Liu (2000). Interaction between Triton X-100 and bovine serum albumin. Chin. J. Anal. Chem., 28: 699-701.

Xiaohui Wangc, Hongjin Chang, Juan Xie, Baozhou Zhao, Botong Liu, Shuilin Xu, Wenbo Pei, Na Ren, Ling Huang and Wei Huang (2014). Recent developments in lanthanide-based luminescent probes. Biochim. Biophys. Journal of Coordination Chemistry Review, 273-274: 201212.

\section{رقائق معايرة دقيقة جديدة ذات إنتاجية عالية لتقدير المبيدات الفسفورية العضوية في العينات البيئية \\ حسن احمد عزب، زينب محمد أنور، جاسر محمد خيرى، أسامة عبد القادر \\ قسم الكيمياءـ كلية العلوم - جامعة قناة السويس- الإسماعيلية}

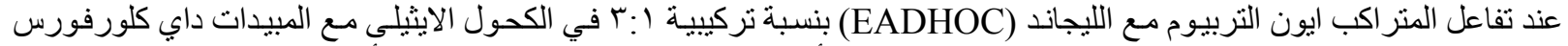

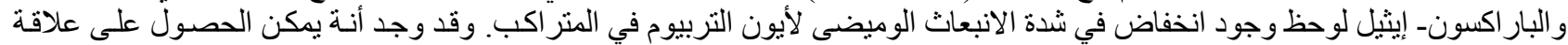

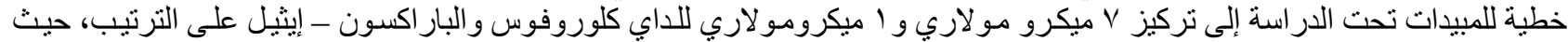

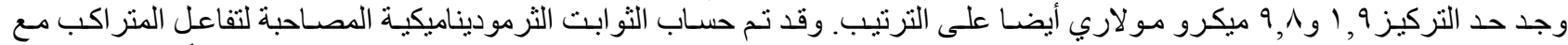

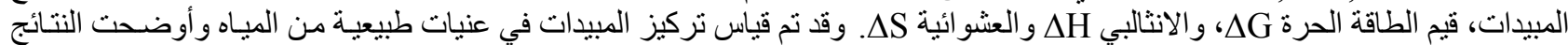
أنه بمكن تحديد تركيز ات مختلفة من المبيدات الفئي الفسفورية بدقة عالية. 